problems, but the whole of its time, as its function is to advise on the administration of the Act; but nine-tenths of the administrative problems with which it has to deal will touch on subjects in which the knowledge of the expert ophthalmic surgeon is required. I feel sure that if Mr. Hayes Fisher had not been so tender in his consideration for the hard-worked ophthalmic specialist and had himself trespassed on the time of any one of them for half an hour they could have adduced evidence sufficient to convince him of the need of constant and primary expert assistance on such a committee rather than intermittent and secondary.

Yours, \&c.,

OphTHALMIC SURGEON.

HARLEy STREeT,

December 11 .

It may be mentioned that the original Departmental Committee had three medical men upon it, one of whom was an ophthalmic surgeon, Mr. Harold B. Grimsdale. This Committee invited the Royal Society of Medicine to assist them in their deliberations and a subcommittee of the Section of Ophthalmology devoted much time and attention to the subject. The Report shows that full use was made of their labours. In the ordinary affairs of civil life it would not be thought courteous to obtain the gratuitous services of experts and then proceed to put their recommendations into action without inviting their co-operation. "Under existing circumstances" there may still be ophthalmic surgeons, whose offers to the War Office have not been accepted-have, indeed, often been entirely ignored-and who are sufficiently free to undertake other duties. In any case, they themselves are the best judges of the time which they have at their disposal, and Mr. Hayes Fisher's polite excuses serve but to accuse him of consistency with the pernicious traditions of Government officials.

\title{
A National Ophthalmological Advisory Committee
}

In an annotation contained in the BRITISH JOURNAL OF OPHTHALMOLOGY of November (p. 678), the suggestion was made that all problems having an ophthalmological bearing arising in any of the Government departments should be referred to a standing advisory committee composed of ophthalmic surgeons. In the present number we publish the report of the Committee of the Ophthalmological Society on Standards of Vision, which includes their correspondence with the War Office, and in the previous annotation we draw attention to the appointment of an Advisory Committee of the Local Government Board on the care of the blind. In both cases we regard the official 
attitude as manifestly unreasonable and calculated to deprive the State of valuable services willingly offered. It is clear that the traditional attitude is so firmly fixed that no ordinary measures will serve to modify it. Government departments are usually very' ready to accept assistance in the many cases in which they are faced with problems which they are unable themselves to solve, though they display a coy reluctance in allowing their advisers any part in the practical application of suggested remedies. So long as this state of affairs persists - and it seems likely to be permanentit is our patriotic duty to supply the best information we can, and thus at least minimise the defects of the system. As there is not the slightest likelihood of a National advisory ophthalmological committee being appointed by the Government, the next best procedure would be for the Ophthalmological Society of the United Kingdom and the Section of Ophthalmology of the Royal Society of Medicine to combine their forces, have a meeting during the next Congress in London in May, and appoint a committee of ten or twelve members to act as a consultative body, and to watch over the public interests of ophthalmology and of ophthalmic surgeons.

\section{Literature for the Blind}

The blind probably derive more pleasure and solace from reading than from any other form of entertainment in which they can indulge without the help of the sighted. It is, therefore, essential not only that the blind should be taught to read, but that an abundance of literature of many varieties should be provided for them. Apropos of the Report of the Departmental Committee on the Welfare of the Blind (see p. 29) the following information concerning the amount and kind of literature available for the blind in the United Kingdom cannot fail to be of interest.

The Census of 1911 gives the number of totally blind in Great Britain and Ireland as 33,965 ; it is probable that not more than two-thirds of this number are readers, but it is to be borne in mind that the percentage of blind who are taught to read is now much higher than it was a quarter of a century ago.

The National Library for the Blind (Tufton Street, Westminster), which is housed in a building recently purchased and presented to the library by the Carnegie Trustees, is the largest and most important organization for the distribution of books and music in embossed type. It contains, approximately, 40,000 volumes, representing between 7,000 and 8,000 separate works. The following rough grouping of the books in the library shows that a goodly variety of literature is provided: Travel, foreign languages, science and education, essays and belles lettres, history, biography, poetry and drama, 